\title{
Method validation and preliminary qualification of pharmacodynamic biomarkers employed to evaluate the clinical efficacy of an antisense compound (AEG35I56) targeted to the X-linked inhibitor of apoptosis protein XIAP
}

\author{
J Cummings*,, , M Ranson ${ }^{2}$, E LaCasse ${ }^{3}$, JR Ganganagari ${ }^{2}$, M St-Jean ${ }^{3}$, G Jayson ${ }^{2}$, J Durkin $^{3}$ and C Dive' \\ 'Clinical and Experimental Pharmacology, Paterson Institute for Cancer Research, University of Manchester, Wilmslow Road, Manchester M20 4BX, \\ England, UK; ${ }^{2}$ Department of Medical Oncology, Christie Hospital NHS Trust, Wilmslow Road, Manchester M20 4BX, England, UK; ${ }^{3}$ Aegera Oncology \\ Inc., CHEO Research Institute, 40 I Smyth Rd, Ottawa, Ontario, Canada KIH $8 \mathrm{LI}$
}

\begin{abstract}
Data are presented on pharmacodynamic (PD) method validation and preliminary clinical qualification of three PD biomarker assays. M65 Elisa, which quantitates different forms of circulating cytokeratin 18 (CK I8) as putative surrogate markers of both apoptotic and nonapoptotic tumour cell death, was shown to be highly reproducible: calibration curve linearity $r^{2}=0.996$, mean accuracy $>91 \%$ and mean precision $<3 \%, n=27$. Employing recombinant $(r)$ CKI8 and caspase cleaved CKI8 (CKI8 Asp ${ }^{396}$ neo-epitope) as external standards, kit to kit reproducibly was $<6 \%(n=19)$. rCKI 8 was stable in plasma for 4 months at $-20^{\circ} \mathrm{C}$ and $-80^{\circ} \mathrm{C}$, for 4 weeks at $4^{\circ} \mathrm{C}$ and had a half-life of 2.3 days at $37^{\circ} \mathrm{C}$. Cytokeratin $18 \mathrm{Asp}{ }^{396} \mathrm{NE}$, the M30 Apoptosense Elisa assay antigen, was stable in plasma for 6 months at $-20^{\circ} \mathrm{C}$ and $-80^{\circ} \mathrm{C}$, for 3 months at $4^{\circ} \mathrm{C}$, while its half-life at $37^{\circ} \mathrm{C}$ was 3.8 days. Within-day variations in endogenous plasma concentrations of the M30 and M65 antigens were assessed in two predose blood samples collected from a cohort of 15 ovarian cancer patients receiving carboplatin chemotherapy and were shown to be no greater than the variability associated with methods themselves. Between-day fluctuations in circulating levels of the M30 and M65 antigens and in XIAP mRNA levels measured in peripheral blood mononuclear cells by quantitative (q) RT-PCR were evaluated in two predose blood samples collected with a 5- to 7-day gap from 23 patients with advanced cancer enrolled in a phase I trial. The mean variation between the two pretreatment values ranged from 13 to 14 to 25\%, respectively, for M65, M30 and qRT-PCR. These data suggest that the M30 and M65 Elisa's and qRT-PCR as PD biomarker assays have favourable performance characteristics for further investigation in clinical trials of anticancer agents which induce tumour apoptosis/necrosis or knockdown of the anti-apoptotic protein XIAP.

British Journal of Cancer (2006) 95, 42-48. doi:I0.1038/sj.bjc.6603220 www.bjcancer.com
\end{abstract}

(c) 2006 Cancer Research UK

Keywords: M65 Elisa; M30 Apoptosense; quantitative RT-PCR; validation; stability, biomarker variability

\begin{abstract}
AEG35156 is a second generation, mixed backbone, 19-mer antisense oligonucleotide targeting the inhibitor of apoptosis protein XIAP and is currently undergoing Phase I clinical evaluation at two centres in the UK (Ranson et al, 2005). Considerable evidence has now accrued through application of a broad range of technologies to a wide spectrum of in vitro and in vivo model systems to substantiate XIAP as a valid molecular target in cancer therapeutics (Lacasse et al, 2005; Wright and Duckett, 2005; Schimmer et al, 2006). A unique feature of the ongoing AEG35156 clinical studies is that a number of pharmacodynamic (PD) biomarker assays have been incorporated into the trial design in order to seek confirmatory evidence of target knockdown and concomitant downstream effects. In addition many other anticancer agents act by inducing apoptosis or necrosis and reliable biomarkers of drug effect are required (Bast et al, 2005; Ludwig and Weinstein, 2005).
\end{abstract}

*Correspondence: Dr J Cummings; E-mail: jcummings@picr.man.ac.uk Received 30 March 2006; revised 12 May 2006; accepted 17 May 2006
In a recent publication, analytical method validation of three different PD biomarker assays was reported: quantitative RT - PCR (qRT - PCR) for XIAP mRNA expression, Western blot analysis for XIAP protein expression, and a novel plasma Elisa assay (M30 Apoptosense) as a surrogate marker of tumour cell apoptosis (Cummings et al, 2005). During that study method validation was conducted in accordance with available internationally recognised bioanalytical guidelines established by the pharmaceutical industry, but primarily utilised in drug and safety monitoring (Shah et al, 2000; Miller et al, 2001). There is a growing acknowledgement that these guidelines are not sufficiently flexible to accommodate the many different categories of PD assays that are employed during anticancer drug development of molecularly targeted agents (Lee et al, 2005). It is now also evident that qualification of a biomarker is a multistage process requiring a concerted team effort often paralleling the drug development cycle (Colburn, 2003; Benowitz, 2004; Ransohoff, 2004; Ludwig and Weinstein, 2005). For PD biomarker assays at least four distinct categories were identified each requiring evaluation of a different set of 
performance criteria: definitive quantitative (e.g. mass spectrometry), relative quantitative (e.g. Western blot analysis), quasiquantitative (e.g. qRT-PCR) and qualitative (e.g. immunohistochemistry) (Lee et al, 2005).

A vital component in PD biomarker validation is the establishment of its pretreatment range and inherent biovariability, in order to assess the likelihood that the technology of choice and trial design have the statistical and technological resolving power to discriminate between normal background biologic variation and a drug-induced effect (Lee et al, 2005). In the present paper, analytical validation of a fourth PD assay, the M65 Elisa (Kramer et al, 2004), is described, along with long term stability studies on the antigens for this assay as well as for M30 Apoptosense (Biven et al, 2003; Kramer et al, 2004). In addition, an evaluation of predose biomarker variability in cancer patients is presented for the M30 and M65 cell death Elisa's and a qRT-PCR method for XIAP mRNA.

\section{MATERIALS AND METHODS}

\section{Reagents}

Custom synthesised PCR primers for XIAP, the XIAP-specific Taqman probe and all other core reagents for $\mathrm{qRT}-\mathrm{PCR}$ were as previously reported in full (Cummings et al, 2005). Staurosporine was from the Sigma Chemical Company (Poole, England, UK). Recombinant human Cytokeratin 18 (rCK18, catalogue number RDI-PRO62217) was from Research Diagnostics Inc. (Flanders, NJ, USA) and upon arrival was separated into $1 \mu \mathrm{g}$ aliquots and stored at $-80^{\circ} \mathrm{C}$ before use. Caspase cleaved CK18 Asp $^{396}$ neo-epitope (CK18 Asp $^{396} \mathrm{NE}$, see Figure 1) was produced by incubation of MDA-MB-231/X-G4 cells (XIAP knockdown) (McManus et al, 2004) with $1 \mu \mathrm{M}$ staurosporine for $48 \mathrm{~h}$, under conditions resulting in maximum induction of apoptosis and optimal release of the $21 \mathrm{kDa}$ peptide fragment into tissue culture media (Bantel et al, 2004; Cummings et al, 2005). The conditioned media was centrifuged at $1000 \mathrm{~g}$ for $20 \mathrm{~min}$ to remove cellular debris and the supernatant was adjusted with fresh media to yield a stock concentration of $\mathrm{M} 30$ antigen of $10000 \mathrm{Ul}^{-1}$, where $1 \mathrm{U}$ is equivalent to $1.24 \mathrm{pmol}$ of peptide (Ueno et al, 2003). The stock solution of $\mathrm{M} 30$ antigen was aliquoted and stored at $-80^{\circ} \mathrm{C}$ before use. The M30 Apoptosense and M65 Elisa kits were both obtained from PEVIVA AB (Bromma, Sweden). All other chemicals,

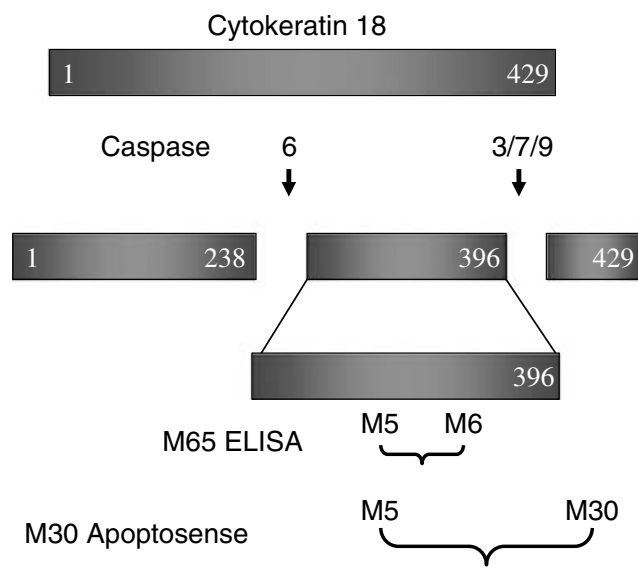

Figure I Schematic representation of the CKI8 epitope map targeted by the antibodies used in the M30 Apoptosense and M65 sandwich Elisa assays. In the case of M65 Elisa the M6 antibody acts as the catcher and M5 as detection antibody. For the M30 Apoptosense assay M5 was the catcher and HRP-conjugated M30 the detection antibody. reagents and buffers were of the highest grade available commercially and water was purified and deionised in a Millipore Elix 3 system (Millipore, Watford, England, UK).

Preparation of quality control samples of volunteer human plasma containing either M30 or M65 antigens for stability studies

Blood was collected from a group of healthy volunteers with informed consent in the registered phlebotomy centre of the Paterson Institute for Cancer Research, Manchester, UK. Plasma was immediately separated by centrifugation at $1000 \mathrm{~g}$ for $10 \mathrm{~min}$ and the supernatants pooled. To one-half of the pooled plasma was added freshly thawed rCK18 to achieve a final concentration of M65 antigen of circa $1500 \mathrm{Ul}^{-1}$ and to the other half of the pool was added CK18 $\mathrm{Asp}^{396} \mathrm{NE}$ to achieve a final concentration of M30 antigen of circa $800 \mathrm{Ul}^{-1}$. Each lot of pooled plasma was thoroughly mixed and centrifuged, before aliquoting into approximately 200 individual $1.5 \mathrm{ml}$ polypropylene tubes to be used as QC samples in long-term stability studies and in method validation of the M65 assay.

\section{Collection of predose blood samples from cancer patients for M65 and M30 Elisa analysis}

Samples were utilised from two separate trials following informed consent. In the first, two predose samples were obtained from cancer patients with a 5- to 7-day gap between collections as part of a phase I trial of the XIAP inhibitor AEG35156. In this case, $5 \mathrm{ml}$ of venous blood was drawn into a vacutainer tube containing heparin anticoagulant. Within $30 \mathrm{~min}$ of collection bloods were centrifuged at $1000 \mathrm{~g}$ for $10 \mathrm{~min}$ to obtain plasma and the plasma transferred to $3 \mathrm{ml}$ polypropylene cyrotubes. Tubes were then frozen at $-20^{\circ} \mathrm{C}$ within $30 \mathrm{~min}$ and transferred to $-80^{\circ} \mathrm{C}$ within $3 \mathrm{~h}$. In the second study, two predose samples were obtained from cancer patients within the same day. The aim of this study was to establish the baseline values and variability in endogenous plasma levels of full-length CK18 and CK18 Asp ${ }^{396} \mathrm{NE}$ in patients with ovarian cancer before and during treatment with platinum based chemotherapy. The sample handling protocol was essentially the same as in the AEG35156 phase I trial. All samples from both trials were analysed within 4 months of collection.

\section{The M65 Elisa assay}

The M65 Elisa assay is a commercially available kit based on a 96well plate format, it consists of a seven-point calibration curve $\left(125-2000 \mathrm{Ul}^{-1}\right.$ of antigen) and certified low and high quality controls (QC, circa 200 and $1000 \mathrm{Ul}^{-1}$ ), and was operated according to the manufacturer's instructions. In brief, $25 \mu \mathrm{l}$ of sample (standard, blank, QC, or patient plasma sample) was added to each well, which was coated with a mouse monoclonal 'catcher' antibody that binds to an epitope on CK18 (M6 antibody, see Figure 1). Simultaneously, $75 \mu \mathrm{l}$ of HRP-conjugated monoclonal antibody (M5) solution was added to act as the detection antibody (Kramer et al, 2004). Samples were then incubated for $2 \mathrm{~h}$ at room temperature with constant shaking, after which excess unbound conjugate was removed by addition of the wash solution, times five. Colour development was achieved by incubation with $200 \mu \mathrm{l}$ of $3,3^{\prime}, 5,5^{\prime}$-tetramethyl-benzidine solution for $20 \mathrm{~min}$ in the dark. The reaction was stopped with $50 \mu \mathrm{l}$ of $1.0 \mathrm{M}$ sulphuric acid and absorbance was finally measured in a microplate reader at $450 \mathrm{~nm}$. By plotting a standard curve of known concentrations of M65 antigen standards $v s$ absorbance, the amount of antigen in the QCs and unknown samples was calculated by interpolation. The M30 Apoptosense assay was performed as previously published (Cummings et al, 2005). 


\section{Blood collection for RNA extraction and XIAP determination by qRT-PCR}

Venous blood samples (approximately $2.5 \mathrm{ml}$ ) for XIAP mRNA analysis were collected from a cohort of cancer patients entered into the AEG35156 Phase I trial. Two predose samples were obtained from the patients with normally a 5- to 7-day gap between collections as part of the full PD protocol. Venous blood samples were collected into $2.5 \mathrm{ml}$ PAXgene Blood RNA extraction tubes (PAXgene Blood RNA kit, PreAnalytiX/Qiagen, Catalogue Number, 762132, Valencia, CA, USA). The PAXgene tubes were inverted 810 times and cells lysed at room temperature for $2-24 \mathrm{~h}$ before being frozen at $-20^{\circ} \mathrm{C}$ after which they were transferred to $-80^{\circ} \mathrm{C}$ storage.

Frozen PAXgene tubes were allowed to thaw for $4 \mathrm{~h}$ before centrifugation at $2490 \mathrm{~g}$ for $20 \mathrm{~min}$ in a swing out rotor and the supernatants discarded (IEC Centra GP8R bench top centrifuge). Pellets were resuspended in RNase-free water $(5 \mathrm{ml})$, further centrifuged as above and finally resuspended in $360 \mu$ l buffer BR 1 (PAXgene Blood RNA kit, PreAnalytiX/Qiagen) by vortexing. Tubes were then incubated for $10 \mathrm{~min}$ at $55^{\circ} \mathrm{C}$ in a $280 \mathrm{~g}$ shakerincubator with $40 \mu \mathrm{l}$ Proteinase $\mathrm{K}$ and $300 \mu \mathrm{l}$ buffer BR2. At the end of the incubation $350 \mu \mathrm{l}$ of $100 \%$ ethanol was added and the total sample was then applied on to the PAXgene extraction column together with $350 \mu \mathrm{l}$ of buffer BR3 and centrifuged at $8000 \mathrm{~g}$ for $1 \mathrm{~min}$ in a minifuge discarding the flow through waste. Next the extraction columns were incubated with DNase I (10 $\mu$ l DNase I stock solution to $70 \mu \mathrm{l}$ Buffer RDD) for $15 \mathrm{~min}$ at room temperature. Extraction columns were then washed with $350 \mu \mathrm{l}$ buffer BR3 as above, followed by two washes and spins with $500 \mu \mathrm{l}$ of buffer BR4, the later performed at maximum speed (16000 g) for 3 min to dry the PAXgene column membrane. The columns were finally eluted with $40 \mu \mathrm{l}$ of buffer BR5 and the eluent collected in a $0.5 \mathrm{ml}$ tube after a spin at $8000 \mathrm{~g}$ for $1 \mathrm{~min}$. The final eluent was incubated for $5 \mathrm{~min}$ at $65^{\circ} \mathrm{C}$ in a heating block, then chilled on ice and the harvested RNA was stored at $-80^{\circ} \mathrm{C}$. qRT - PCR was then performed essentially as described in detail (Fong et al, 2000; McKinnon et al, 2002; Hu et al, 2003; Cummings et al, 2005). All the RT - PCR steps were carried out in an ABI Prism 7700 Sequence Detector, and quantitation was by the cycle threshold (CT) method.

\section{RESULTS AND DISCUSSION}

\section{Method validation of the M65 Elisa assay}

We have previously shown that the M30 assay yields a sigmoidal calibration curve of the type often associated with sandwich Elisa assays (Miller et al, 2001; Cummings et al, 2005). Here, we show that the M65 assay produces a linear calibration curve over the concentration range of $125-2000 \mathrm{U} / \mathrm{l}^{-1}$, with a mean regression correlation coefficient $\left(r^{2}\right)$ value of $0.996 \pm 0.003(n=27)$. The linear response is believed to be due to the high affinity constants $\left(10^{-13} \mathrm{M}\right)$ of the two mouse monoclonal antibodies utilised, M6 and M5 (Kramer et al, 2004), for their respective CK18 epitopes and the subsequent faster reaction kinetics (Peter Björklund, PEVIVA, personal communication). Thus, the M65 Elisa assay only requires a $2 \mathrm{~h}$ incubation time period as compared to a $4 \mathrm{~h}$ incubation for M30 Apoptosense.

The M65 Elisa also proved to be highly reproducible with precision and accuracy ( $\mathrm{P}$ and $\mathrm{A}$ ) based on values obtained using the in kit QCs $\left(200\right.$ and $\left.1000 \mathrm{Ul}^{-1}\right)$ (Table 1). Furthermore, precision and kit to kit reproducibility data were generated by use of independent external standard QCs consisting of both rCK18 and CK18 Asp ${ }^{396}$ NE added to human plasma (see Table 1). These studies were conducted over an 18-month period and were generated after running a total of 27 assays using 19 different kits, comprising three different production batches. Each experiment consisted of a seven point calibration curve run in duplicate, including a blank, while replicates numbers of each QC run per experiment ranged from $n=3-8$. Mean $\mathrm{P}$ and $\mathrm{A}$ achieved with the in kit QCs normally varied by $<5 \%$ with the exception of accuracy for the low QC which varied by $8.3 \%$ (yielding a mean of $91.7 \%$ of that of its nominal value). This bias was introduced exclusively by kits from the earliest production batch, and appeared to be eliminated in the subsequent two production batches. Utilising the external standards, mean kit to kit variations in the concentration of antigen determined was $5.3 \%$ with rCK18 and $4.8 \%$ with CK18 Asp ${ }^{396} \mathrm{NE}$, normally well within the manufacturer's acceptance criteria of 10\%, (http://web.peviva.se/ index.asp).

Unlike the M30 Apoptosense Elisa that relies on caspase cleavage to reveal a neo-epitope mapped to positions 387-396 of CK18 (Ku et al, 1997; Leers et al, 1999), the M65 Elisa utilises the M6 antibody to capture and an HRP-conjugated M5 antibody to detect epitopes present in a domain common to the intact protein as well as the $21 \mathrm{kDa}$ caspase cleaved fragment (see Figure 1) (Kramer et al, 2004). Although, intact CK18 is viewed as a stable insoluble structural component of the intermediate filaments (Fuchs and Weber, 1994), proliferating cells also possess a substantial pool of soluble CK18, which increases upon stress due to remodelling of cellular structure (Chou et al, 1993; $\mathrm{Ku}$ et al, 1997). Recently, cancer cells undergoing necrotic death have been shown to release intact CK18 in a manner analogous to the release of its caspase cleaved fragment from cells undergoing apoptosis (Kramer et al, 2004; Schutte et al, 2004). Thus, the M65 Elisa potentially detects both necrotic and apoptotic components, although it is unclear whether or not this assay is capable of detecting all presently known cell death mechanisms such as autophagy and mitotic catastrophe (Broker et al, 2005). Nevertheless, since both the M30 and M65 assays are calibrated with the same recombinant CK18 peptide fragment (CK18 Asp $^{396} \mathrm{NE}$ ), their readouts are directly comparable and the ratio of the signal measured by each enables differentiation between cell death modes (Kramer et al, 2004). We have confirmed by use of our standard of caspase cleaved CK18 that both assays do indeed produce very similar results, normally within $10 \%$ of each other, whereas the M30 Apoptosense assay exhibits, as expected, very little cross reactivity for intact rCK18.

Table I Reproducibility of the M65 Elisa assay

\begin{tabular}{|c|c|c|c|}
\hline QC standard & Mean accuracy (\%) & Mean precision (\%) & Number of assays \\
\hline
\end{tabular}

Abbreviations: CKI8 = cytokeratin 18; QC = quality controls. 


\section{Stability studies on the M30 and M65 antigens}

Long-term stability studies were conducted in order to establish the maximal period of time that human plasma could be stored at different temperature without in situ analyte degradation occurring. Six-month stability of both the M30 and M65 antigens in pooled volunteer plasma was studied at $4^{\circ} \mathrm{C},-20^{\circ} \mathrm{C}$ and $-80^{\circ} \mathrm{C}$ (Figures 2 and 3, respectively). In addition, plasma containing both M30 and M65 antigens were subjected to three cycles of freeze thawing at $-80^{\circ} \mathrm{C}$ (data not shown).

The M30 antigen (CK18 Asp ${ }^{396}$ NE, see Figure 1) was shown to be stable over 6 months at both $-20^{\circ} \mathrm{C}$ and $-80^{\circ} \mathrm{C}$ (Figure 2), where instability is defined as a significant reduction by Students $t$ test in concentration between two consecutive time points. After 6 months incubation at $-80^{\circ} \mathrm{C}$ instability was demonstrated at the 8 month time with an $11.1 \%$ reduction in value $(P=<0.01)$ (data not shown). At $4^{\circ} \mathrm{C}$ clear fluctuations in concentration were recorded, whereby after 4 months a small but significant reduction in value was observed followed by a larger increase after 6 months.

A small but significant $(P<0.01)$ reduction in concentration of full-length rCK18 occurred after 6 months at both $-20^{\circ} \mathrm{C}$ and $-80^{\circ} \mathrm{C}$ ( 10.9 and $19.9 \%$, respectively) (Figure 3 ) indicating that the stability of the M65 antigen is restricted to only 4 months at these temperatures. Whereas at $4^{\circ} \mathrm{C}$ stability was only evident for 4 weeks, after which time a consistent rise in concentration occurred for up to 3 months before levels started to fall. Samples subjected to three cycles of freeze thawing had no deleterious effect on the concentration of both M30 and M65 antigens.

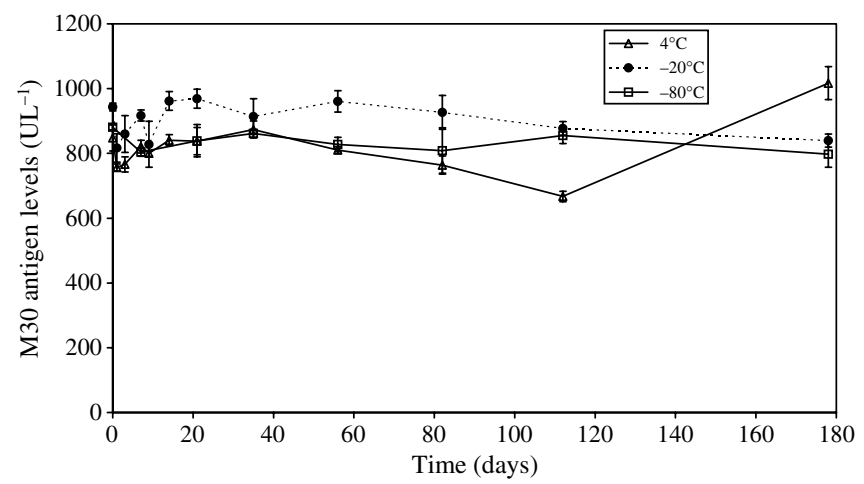

Figure 2 Stability of caspase cleaved CKI8 (Asp ${ }^{396}$ neo-epitope, see Figure I) in human volunteer plasma determined by the M30 Apoptosense assay. Each time point represents the mean value \pm standard deviation (s.d.) of $n=3-8$ replicates.

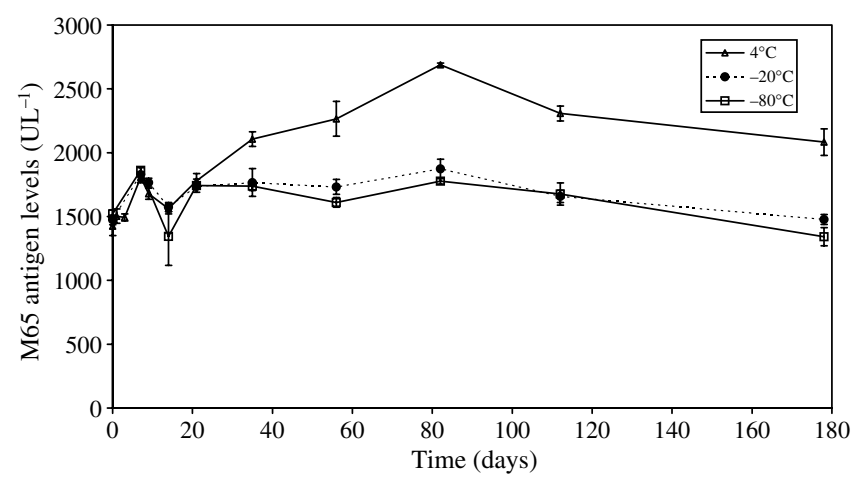

Figure 3 Stability of recombinant human cytokeratin 18 in human volunteer plasma determined by the M65 Elisa assay. Each time point represents the mean value \pm s.d. of $n=3-8$ replicates.
Accelerated stability was also investigated at $37^{\circ} \mathrm{C}$ using individual volunteer plasma samples spiked at a higher concentration of rCK18 in order to accommodate for the more rapid decline in concentration $\left(10000 \mathrm{Ul}^{-1}\right.$, Figure 4$)$. In this case the aim was to address the issue of whether or not the M65 and M30 antigens are sufficiently stable in plasma at body temperatures to provide meaningful quantitative information on the kinetics of cell death occurring at distal sites in the body such as a tumour. Although the early stages of apoptosis occur within minutes, the final stages of lysosomal degradation can extend into hours, depending on cell type and tissue (Holdenrieder and Stieber, 2004a) and a lag period in the region $6-10 \mathrm{~h}$ has been reported before cleaved cytokeratin products are released from apoptotic bodies and necrotic cells (Einarsson and Barak, 1997; Schutte et al, 2004). Nonetheless, the stability studies conducted at $37^{\circ} \mathrm{C}$ yielded a mean half-life of 2.3 days for rCK18 in human plasma (Figure 4), compared to 3.8 days for CK18 Asp $^{396} \mathrm{NE}$ (Cummings et al, 2005).

The presence of different keratins in either plasma or serum of cancer patients has been recognised for many years and used as tumour markers in the diagnosis of cancer (Weber et al, 1984; Sundstrom and Stigbrand, 1994; Silen et al, 1995; Dobashi et al, 2000; Barak et al, 2004; Seregni et al, 2004). Therefore, it may be surprising that few publications have focused on the formal stability of these proteins as analytes in the systematic manner reported herein. Perhaps, in the case of keratins long term stability has always been presumed. Keratins are primarily responsible for providing cytoskeletal rigidity, and are now even believed to protect cells against chemical toxicity (Owens and Lane, 2003). Indeed, good physical and chemical stability has been demonstrated in a number of studies, especially in the case of the caspase cleaved fragments of CK18 (Ku et al, 1997; Carr, 2000; Aho, 2004). We have also confirmed that caspase cleaved CK18 is considerably more stable than the intact protein.

An unexpected finding of this work was that statistically significant increases in concentration of both intact CK18 and its caspase cleaved fragment occurred during the stability studies. A similar effect has also been observed in long-term stability of CK18 $\mathrm{Asp}^{396} \mathrm{NE}$ in tissue culture media (Cummings et al, 2005). Investigations on keratin $8 / 18$ breakdown and reorganisation during apoptosis have shown that the M30 antigen is released from apoptotic cells as large aggregates, which are believed to promote their stability in the circulation, including avoidance of uptake and clearance by the reticuloendothelial system (Schutte et al, 2004). It is likely that the CK18 Asp ${ }^{396} \mathrm{NE}$ standard used in the present work, which was generated by the induction of apoptosis in cancer cells in vitro, also consists of aggregates. The possibility exits that with time these aggregates dissociate to reveal more epitope sites for antibody interaction thus giving the appearance of an increase

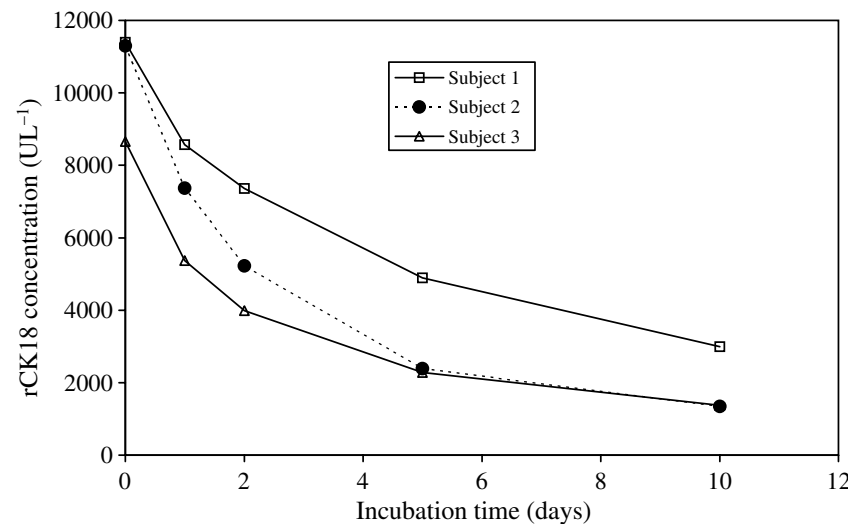

Figure 4 Stability of recombinant human CKI8 in human volunteer plasma incubated at $37^{\circ} \mathrm{C}$ determined by the M65 Elisa assay. Each time point represents duplicate measurements. The mean half-life was 2.3 days. 
in concentration. Cytokeratin 18 also has a strong propensity to form higher complexes both with keratin and non-keratin proteins (Liao and Omary, 1996; Hofmann and Franke, 1997; Coulombe et al, 1998) and can be detected in the circulation as a range of small and large polymeric protein complexes referred to as tissue polypeptide-specific antigen (TPS) (Rydlander et al, 1996). Therefore, as with the M30 antigen, it is conceivable that association occurs in situ when rCK18 is added to plasma and that with time these complexes also slowly disassociate, before the onset of proteolytic destruction or chemical degradation. Alternatively, in the case of intact rCK18 protein unfolding could occur with time and that might increase the accessibility of the detection antibody (M5) for its epitope. Possible explanations for the increase in concentration are currently under investigation.

Within-day and between-day variability in baseline values of M30 and M65 antigens in cancer patients

Within-day variations in the baseline levels of circulating M30 and M65 antigens detected in a cohort of 15 ovarian cancer patients are

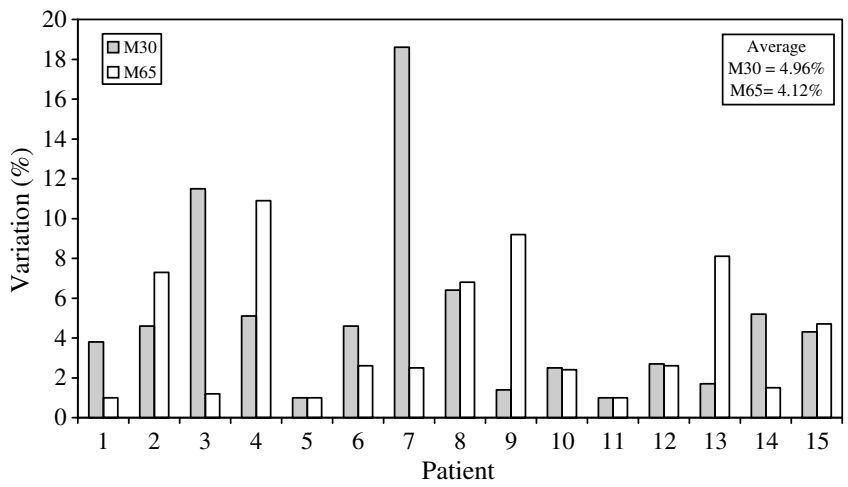

Figure 5 Within-day variations in baseline, predose values of M30 and M65 antigens in plasma of ovarian cancer patients before treatment with Carboplatin. Two separate blood samples were obtained with a I $-8 \mathrm{~h}$ gap between collections. The percentage difference in the two results for each patient is presented in the graph. In these studies the M65 assay was used to determine the M65 antigen, while the M30 Apoptosense assay was used to determine the M30 antigen.

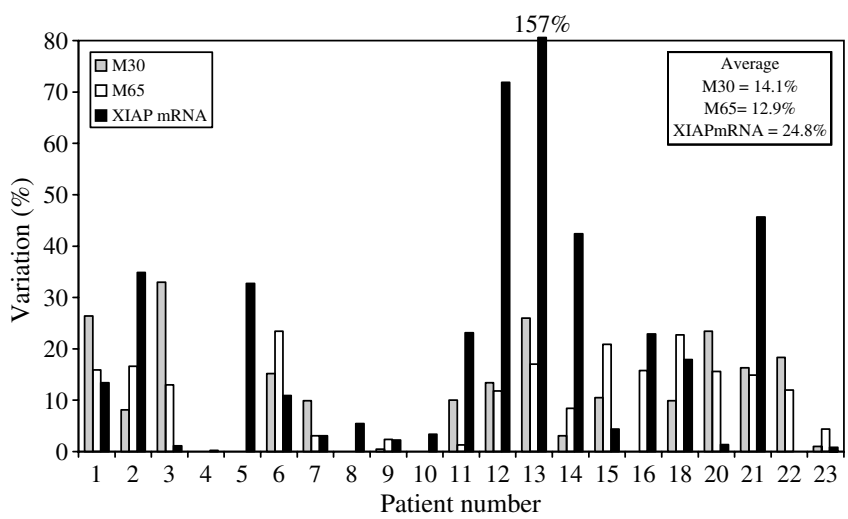

Figure 6 Between-day variations in baseline, predose plasma values of M30 and M65 antigens and XIAP mRNA measured in PBMCs by qRTPCR. Two separate blood samples were obtained from patients entered into the AEG35 I 56 phase I with a 5- to 7-day gap between collections. The percentage difference in the two results for each patient is presented in the graph. In these studies the M65 assay was used to determine the M65 antigen, while the M30 Apoptosense assay was used to determine the M30 antigen. presented in Figure 5, while between-day variations obtained by analysis of two predose samples collected 5-7 days apart from patients entered into the AEG35156 trial are shown in Figure 6. In these studies, the M65 assay was used to determine M65 antigen, while the M30 Apoptosense assay was used to determine the M30 antigen. For within-day, the percentage differences measured (5.0\% average for M30 and $4.1 \%$ average for M65) were within, or at least close to, the normal levels of variability associated with the methods indicating a comparatively small contribution from the biomarker itself. These data are in contrast to many typical plasma PD assays which are often associated with $30 \%$ or greater imprecision (Miller et al, 2001; Lee et al, 2005).

In the case of between-day (Figure 6), a much greater level of variation was detected, as might be expected, which clearly included a component due to biological variability. Nonetheless, the mean variation was $14.1 \%$ for M30 and $12.9 \%$ for M65 and only in one example (M30 for patient 3) did this value exceed $30 \%$ (Miller et al, 2001; Lee et al, 2005).

Traditionally, detection of a keratin antigen in serum or plasma, such as tissue polypeptide antigen (TPA, fragments of CK8, 18 and 19), TPS (CK18 fragments and complexes) and CYFRA 21-1 (caspase cleaved CK19), has been viewed as a marker of bulk tumour burden (Barak et al, 2004; Seregni et al, 2004) while, some reports have suggested that they might also predict treatment outcome and overall survival (Einarsson and Barak, 1997; Takada et al, 2004). However, it is now believed that the presence of M30, M65 and TPS antigens in the circulation may be more indicative of active processes taking place in the tumour such as apoptosis or other forms of cell death (Einarsson and Barak, 1997; Ueno et al, 2003; Kramer et al, 2004; Schutte et al, 2004). Indeed, other keratin markers such as TPA and CYFRA21-1, which consist of caspase cleaved fragments, are now also being proposed to be markers of apoptosis rather than tumour volume (Dohmoto et al, 2001; Kramer et al, 2004). Thus, the between-day fluctuations observed in the present study in baseline levels of M30 and M65 are more likely to be illustrative of tumour growth dynamics reflecting the balance between cellular proliferation and attrition due to cell death (Evan and Vousden, 2001; Lowe et al, 2004).

The ideal circulating surrogate cancer PD biomarker assay would be specific for tumour cells (Levenson, 2004; Lee et al, 2005). M30 and M65 Elisa's do show a higher degree of specificity compared to other surrogate markers of cell death such as serum nucleosomal DNA Elisa (nDNA) (Holdenrieder and Stieber, $2004 a, b)$, in that they are not subject to interference by bone marrow cell death. Notwithstanding, the M30 and M65 Elisa's would not be capable of distinguishing between circulating CK18 forms arising from normal tissue cell death as compared to tumour cell death. A spate of recent publications have reported that the M30 assay will detect an increased signal in the serum of patients with chronic hepatitis, liver toxicity due to viral infection and critical illness due to sepsis (Bantel et al, 2004; Roth et al, 2004; Kronenberger et al, 2005). These medical conditions, at least in an attenuated form, may also be present in cancer patients due to issues such as general state of health, presence of viral infections and morbidity caused by the toxic side effects of therapy. Nonetheless, in the present study over a 5-7 days period in a group of 23 patients variations in the baseline levels of the M30 and M65 assays did not normally exceed 30\%, whereas by contrast in sepsis a $400 \%$ increase in circulating M30 was detected (Roth et al, 2004), in fibrotic liver injury and chronic hepatitis a $250 \%$ increase occurred (Kronenberger et al, 2005) and after treatment with estamustine/vinorelbine chemotherapy a greater than $200 \%$ increase has been reported (Kramer et al, 2004). Indeed, taking a two-fold increase in signal over mean noise as significant (Kramer et al, 2004), this would translate into an increase of $>28 \%$ for M30 and $>26 \%$ for M65 being characterised as a positive result. Clearly the M30 and M65 have considerable spare dynamic range to record even a modest effect on tumour cell death/apoptosis. 
Predose studies in cancer patients on the baseline values and variability in XIAP mRNA expression determined by qRT - PCR

The graph of between-day variations in predose baseline levels of XIAP mRNA in peripheral blood mononuclear cells (PBMCs) is to found in Figure 6. Here, the mean variation was established to be $25 \%$, ranging from 0.2 to $157 \%$. These values are higher than for the M30 and M65 and this was surprising, for two reasons. First, although GRT-PCR is only considered a quasiquantitative method, since it lacks calibration with an authentic standard, it nevertheless generates numerical results, with a high degree of precision, normally less than $5 \%$ and often exceeding the M30 and M65 Elisa's in performance (Dumur et al, 2002; Jones et al, 2003; Cummings et al, 2005). Second, qRT - PCR of XIAP mRNA should be subject to fewer potential variables than the M30 and M65 assays (see above). Thus, we believe that the high degree of variability observed in Figure 6 is probably due to genuine between-day fluctuations in XIAP mRNA expression in the two predose PBMC samples collected from the different cancer patients. To the best of our knowledge, no similar study has been published addressing the issue of biomarker variability in XIAP mRNA levels in PBMCs in cancer patients or normal volunteers. The differences we observed may possibly be explained either by changes in leucocyte populations expressing varying amounts of XIAP, and/or increases in cellular XIAP levels due to cell division or stimulation with G-CSF or GM-CSF. Both these cytokines have been reported to induce XIAP in leucocytes or AML cells at the protein level (Lin et al, 2002; Zhang et al, 2002; O'Neill et al, 2004).

The measurement of XIAP mRNA expression in PBMCs represents the primary PD assay being utilised in the AEG35156 trial (Cummings et al, 2005). Current thinking suggests that a total knockout of XIAP in tumour would not necessarily be required rather a partial knockdown may be sufficient to lower the apoptotic threshold to take advantage of the intrinsic proapoptotic signalling cascades presumed to be operative in many cancers (Kaufmann and Vaux, 2003; Reed, 2003; Wright and Duckett, 2005). Therefore, only a $50 \%$ reduction may be sufficient to produce a therapeutic effect (Lacasse et al, 2005). Returning to the $2 \times$ signal to noise rule, in the case of the present qRT-PCR method, a knockdown of greater than $50 \%$ would be required to be considered a valid result, although even here one must be aware that extreme outliers are not uncommon (Figure 6). To counteract this problem a potential solution may be to conduct repeated and relatively frequent determinations of XIAP mRNA levels during therapy where a consistent trend may emerge that can then be more confidently distinguished from background variability.

It should be noted that the number of patients employed in both trials to evaluate variability in baseline values of M30 and M65 antigens and XIAP mRNA are based on typical phase I trial numbers (15-23). The present studies are intended as a first stage, and have yielded encouraging results. We are in the process of conducting further and larger clinical studies utilising the M30 and M65 assays as biomarkers of tumour cell death, not just from the point of view of method validation and baseline studies, but eventually to provide definitive proof or otherwise as to the clinical validity and utility of M30 and M65 as surrogate PD biomarkers of tumour cell death - biomarker qualification (Lee et al, 2005).

In summary, data are presented demonstrating that the M65 Elisa is a highly reproducible assay for the determination of CK18 and CK18 Asp ${ }^{396} \mathrm{NE}$ in human plasma. The stability studies have revealed that caspase cleaved CK18 is more stable than the intact protein and that long-term storage of samples is not recommended for more than 4 months even at $-20^{\circ} \mathrm{C}$ and $-80^{\circ} \mathrm{C}$. Finally, we show in patient studies that the typical baseline variation in the analytes of the M30 and M65 Elisa's and a qRT-PCR method for XIAP mRNA is comparatively small at 14,13 and $25 \%$, respectively.

\section{REFERENCES}

Aho S (2004) Plakin proteins are coordinately cleaved during apoptosis but preferentially through the action of different caspases. Exp Dermatol 13: $700-707$

Bantel H, Lugering A, Heidemann J, Volkmann X, Poremba C, Strassburg CP, Manns MP, Schulze-Osthoff K (2004) Detection of apoptotic caspase activation in sera from patients with chronic HCV infection is associated with fibrotic liver injury. Hepatology 40: 1078-1087

Barak V, Goike H, Panaretakis KW, Einarsson R (2004) Clinical utility of cytokeratins as tumor markers. Clin Biochem 37: 529-540

Bast Jr RC, Lilja H, Urban N, Rimm DL, Fritsche H, Gray J, Veltri R, Klee G, Allen A, Kim N, Gutman S, Rubin MA, Hruszkewycz A (2005) Translational crossroads for biomarkers. Clin Cancer Res 11: 6103-6108

Benowitz S (2004) Biomarker boom slowed by validation concerns. J Natl Cancer Inst 96: 1356-1357

Biven K, Erdal H, Hagg M, Ueno T, Zhou R, Lynch M, Rowley B, Wood J, Zhang C, Toi M, Shoshan MC, Linder S (2003) A novel assay for discovery and characterization of pro-apoptotic drugs and for monitoring apoptosis in patient sera. Apoptosis 8: $263-268$

Broker LE, Kruyt FA, Giaccone G (2005) Cell death independent of caspases: a review. Clin Cancer Res 11: 3155-3162

Carr NJ (2000) M30 expression demonstrates apoptotic cells, correlates with in situ end-labeling, and is associated with Ki-67 expression in large intestinal neoplasms. Arch Pathol Lab Med 124: 1768-1772

Chou CF, Riopel CL, Rott LS, Omary MB (1993) A significant soluble keratin fraction in simple epithelial cells. Lack of an apparent phosphorylation and glycosylation role in keratin solubility. J Cell Sci 102: $433-444$

Colburn WA (2003) Biomarkers in drug discovery and development: from target identification through drug marketing. J Clin Pharmacol 43: 329-341

Coulombe PA, Wawersik M, Paladini RD, Noensie E (1998) Type I keratin 16 forms relatively unstable tetrameric assembly subunits with various

type II keratin partners: biochemical basis and functional implications. Biol Bull 194: 364-365; discussion 365-366

Cummings J, Ward TH, Lacasse E, Lefebvre C, St-Jean M, Durkin J, Ranson M, Dive C (2005) Validation of pharmacodynamic assays to evaluate the clinical efficacy of an antisense compound (AEG 35156) targeted to the X-linked inhibitor of apoptosis protein XIAP. Br J Cancer 92: $532-538$

Dobashi N, Fujita J, Murota M, Ohtsuki Y, Yamadori I, Yoshinouchi T, Ueda R, Bandoh S, Kamei T, Nishioka M, Ishida T, Takahara J (2000) Elevation of anti-cytokeratin 18 antibody and circulating cytokeratin 18: anti-cytokeratin 18 antibody immune complexes in sera of patients with idiopathic pulmonary fibrosis. Lung 178: 171-179

Dohmoto K, Hojo S, Fujita J, Yang Y, Ueda Y, Bandoh S, Yamaji Y, Ohtsuki Y, Dobashi N, Ishida T, Takahara J (2001) The role of caspase 3 in producing cytokeratin 19 fragment (CYFRA21-1) in human lung cancer cell lines. Int J Cancer 91: 468-473

Dumur CI, Dechsukhum C, Wilkinson DS, Garrett CT, Ware JL, Ferreira-Gonzalez A (2002) Analytical validation of a real-time reverse transcription-polymerase chain reaction quantitation of different transcripts of the Wilms' tumor suppressor gene (WT1). Anal Biochem 309: $127-136$

Einarsson R, Barak V (1997) TPS: a cytokeratin serum tumour marker for effective therapy control of cancer patient with focus on breast cancer. J Clin Ligand Assay 22: 348-351

Evan GI, Vousden KH (2001) Proliferation, cell cycle and apoptosis in cancer. Nature 411: $342-348$

Fong WG, Liston P, Rajcan-Separovic E, St Jean M, Craig CG, Korneluk RG (2000) Expression and genetic analysis of XIAP-associated Factor 1(XAF1) in cancer cell lines. Genomics 70: 113-122

Fuchs E, Weber K (1994) Intermediate filaments: structure, dynamics, function, and disease. Annu Rev Biochem 63: 345-382 
Hofmann I, Franke WW (1997) Heterotypic interactions and filament assembly of type I and type II cytokeratins in vitro: viscometry and determinations of relative affinities. Eur J Cell Biol 72: 122-132

Holdenrieder S, Stieber P (2004a) Apoptotic markers in cancer. Clin Biochem 37: $605-617$

Holdenrieder S, Stieber P (2004b) Therapy control in oncology by circulating nucleosomes. Ann NY Acad Sci 1022: 211-216

Hu Y, Cherton-Horvat G, Dragowska V, Baird S, Korneluk RG, Durkin JP, Mayer LD, LaCasse EC (2003) Antisense oligonucleotides targeting XIAP induce apoptosis and enhance chemotherapeutic activity against human lung cancer cells in vitro and in vivo. Clin Cancer Res 9: 2826-2836

Jones CD, Yeung C, Zehnder JL (2003) Comprehensive validation of a realtime quantitative bcr-abl assay for clinical laboratory use. Am J Clin Pathol 120: $42-48$

Kaufmann SH, Vaux DL (2003) Alterations in the apoptotic machinery and their potential role in anticancer drug resistance. Oncogene 22: 7414- 7430

Kramer G, Erdal H, Mertens HJ, Nap M, Mauermann J, Steiner G, Marberger M, Biven K, Shoshan MC, Linder S (2004) Differentiation between cell death modes using measurements of different soluble forms of extracellular cytokeratin 18. Cancer Res 64: 1751-1756

Kronenberger B, Wagner M, Herrmann E, Mihm U, Piiper A, Sarrazin C, Zeuzem S (2005) Apoptotic cytokeratin 18 neoepitopes in serum of patients with chronic hepatitis C. J Viral Hepat 12: 307-314

Ku NO, Liao J, Omary MB (1997) Apoptosis generates stable fragments of human type I keratins. J Biol Chem 272: 33197-33203

Lacasse EC, Kandimalla ER, Winocour P, Sullivan T, Agrawal S, Gillard JW, Durkin J (2005) Application of XIAP Antisense to Cancer and Other Proliferative Disorders: Development of AEG35156/GEM(R)640. Ann NY Acad Sci 1058: 215-234

Lee JW, Weiner RS, Sailstad JM, Bowsher RR, Knuth DW, O'Brien PJ, Fourcroy JL, Dixit R, Pandite L, Pietrusko RG, Soares HD, Quarmby V, Vesterqvist OL, Potter DM, Witliff JL, Fritche HA, O'Leary T, Perlee L, Kadam S, Wagner JA (2005) Method validation and measurement of biomarkers in nonclinical and clinical samples in drug development: a conference report. Pharm Res 22: 499-511

Leers MP, Kolgen W, Bjorklund V, Bergman T, Tribbick G, Persson B, Bjorklund P, Ramaekers FC, Bjorklund B, Nap M, Jornvall H, Schutte B (1999) Immunocytochemical detection and mapping of a cytokeratin 18 neo-epitope exposed during early apoptosis. J Pathol 187: 567-572

Levenson VV (2004) Biomarkers: diagnostic highlights and surrogate end points. Cambridge Healthtech Institute's biomarker series: biomarker validation: bringing discovery to the clinic \& cancer biomarkers: from discovery to clinical practice. May 3-5, 2004, Philadelphia, Pennsylvania, USA. Pharmacogenomics 5: 459-461

Liao J, Omary MB (1996) 14-3-3 proteins associate with phosphorylated simple epithelial keratins during cell cycle progression and act as a solubility cofactor. J Cell Biol 133: $345-357$

Lin $\mathrm{H}$, Chen C, Li X, Chen BD (2002) Activation of the MEK/MAPK pathway is involved in bryostatin1-induced monocytic differenciation and up-regulation of X-linked inhibitor of apoptosis protein. Exp Cell Res 272: $192-198$

Lowe SW, Cepero E, Evan G (2004) Intrinsic tumour suppression. Nature 432: $307-315$

Ludwig JA, Weinstein JN (2005) Biomarkers in cancer staging, prognosis and treatment selection. Nat Cancer Rev 5: 845-856

McKinnon SJ, Lehman DM, Tahzib NG, Ransom NL, Reitsamer HA, Liston P, LaCasse EC, Li Q, Korneluk RG, Hauswirth WM (2002) Baculoviral IAP repeat-containing-4 protects optic nerve axons in a rat glaucoma model. Mol Ther 5: 780-787

McManus DC, Lefebvre CA, Cherton-Horvat G, St-Jean M, Kandimalla ER, Agrawal S, Morris SJ, Durkin JP, Lacasse EC (2004) Loss of XIAP protein expression by RNAi and antisense approaches sensitizes cancer cells to functionally diverse chemotherapeutics. Oncogene 23: 8105-8117
Miller KJ, Bowsher RR, Celniker A, Gibbons J, Gupta S, Lee JW, Swanson SJ, Smith WC, Weiner RS (2001) Workshop on bioanalytical methods validation for macromolecules: summary report. Pharm Res 18: 1373 1383

O'Neill AJ, Doyle BT, Molloy E, Watson C, Phelan D, Greenan MC, Fitzpatrick JM, Watson RW (2004) Gene expression profile of inflammatory neutrophils: alterations in the inhibitors of apoptosis proteins during spontaneous and delayed apoptosis. Shock 21: 512-518

Owens DW, Lane EB (2003) The quest for the function of simple epithelial keratins. Bioessays 25: 748-758

Ransohoff DF (2004) Rules of evidence for cancer molecular-marker discovery and validation. Nat Rev Cancer 4: 309-314

Ranson M, Dive C, Ward TH, Cummings J, Connolly K, Evans S, Robson L, Durkin J, Jolivet J, Jodrell DI (2005) A Phase I Trial of AEG35156 (XIAP antisense)Administered as a 7-day Continuous Intravenous Infusion in Patients with Advanced Tumors. Clin Cancer Res 11: 9116s, C9172

Reed JC (2003) Apoptosis-targeted therapies for cancer. Cancer Cell 3: 17 22

Roth GA, Krenn C, Brunner M, Moser B, Ploder M, Spittler A, Pelinka L, Sautner T, Wolner E, Boltz-Nitulescu G, Ankersmit HJ (2004) Elevated Serum Levels of Epithelial Cell Apoptosis-Specific Cytokeratin 18 Neoepitope M30 in Critically Ill Patients. Shock 22: 218-220

Rydlander L, Ziegler E, Bergman T, Schoberl E, Steiner G, Bergman AC, Zetterberg A, Marberger M, Bjorklund P, Skern T, Einarsson R, Jornvall $\mathrm{H}$ (1996) Molecular characterization of a tissue-polypeptide-specificantigen epitope and its relationship to human cytokeratin 18. Eur J Biochem 241: 309-314

Schimmer AD, Dalili S, Batey RA, Riedl SJ (2006) Targeting XIAP for the treatment of malignancy. Cell Death Differ 13: 179-188

Schutte B, Henfling M, Kolgen W, Bouman M, Meex S, Leers MP, Nap M, Bjorklund V, Bjorklund P, Bjorklund B, Lane EB, Omary MB, Jornvall $\mathrm{H}$, Ramaekers FC (2004) Keratin 8/18 breakdown and reorganization during apoptosis. Exp Cell Res 297: 11-26

Seregni E, Coli A, Mazzucca N (2004) Circulating tumour markers in breast cancer. Eur J Nucl Med Mol Imaging 31(Suppl 1): S15-S22

Shah VP, Midha KK, Findlay JW, Hill HM, Hulse JD, McGilveray IJ, McKay G, Miller KJ, Patnaik RN, Powell ML, Tonelli A, Viswanathan CT, Yacobi A (2000) Bioanalytical method validation-a revisit with a decade of progress. Pharm Res 17: 1551-1557

Silen A, Wiklund B, Andersson EL, Nilsson S (1995) A novel IRMA and ELISA for quantifying cytokeratin 8 and 18 fragments in the sera of healthy individuals and cancer patients. Scand J Clin Lab Invest 55: 153 161

Sundstrom BE, Stigbrand TI (1994) Cytokeratins and tissue polypeptide antigen. Int J Biol Markers 9: 102-108

Takada M, Kataoka A, Toi M, Bando H, Toyama K, Horiguchi S, Ueno T, Linder S, Saji S, Hayashi Y, Funata N, Kinoshita J, Murakami S, Ohono S (2004) A close association between alteration in growth kinetics by neoadjuvant chemotherapy and survival outcome in primary breast cancer. Int J Oncol 25: 397-405

Ueno T, Toi M, Biven K, Bando H, Ogawa T, Linder S (2003) Measurement of an apoptotic product in the sera of breast cancer patients. Eur J Cancer 39: $769-774$

Weber K, Osborn M, Moll R, Wiklund B, Luning B (1984) Tissue polypeptide antigen (TPA) is related to the non-epidermal keratins 8,18 and 19 typical of simple and non-squamous epithelia: re-evaluation of a human tumor marker. EMBO J 3: 2707-2714

Wright CW, Duckett CS (2005) Reawakening the cellular death program in neoplasia through the therapeutic blockade of IAP function. J Clin Invest 115: $2673-2678$

Zhang J, Li Y, Shen B (2002) Up-regulation of XIAP by M-CSF is associated with resistance of myeloid leukemia cells to apoptosis. Leukemia 16: $2163-2165$ 